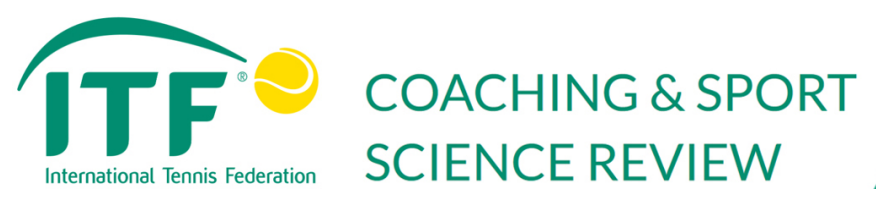

\title{
Hard knocks: Concussion injuries in tennis
}

\author{
Alan J Pearce (AUS) and Janet A Young (AUS)
}

ITF Coaching and Sport Science Review 2016; 70 (24): 5 - 7

\begin{abstract}
Concussions in tennis are rare, but they do occur. As recent case reports have highlighted, players who sustain concussions in tennis can be affected for much longer than expected. This article, written for the coach, outlines the signs of concussion, concussion awareness in tennis, and the coach's role in mitigating risk and managing concussions in their players.
\end{abstract}

Key words: Concussion, Injury, Post concussion syndrome Received: 24 June 2016 Accepted: 27 July 2016 Corresponding author: Janet A Young Email: janet_young7@yahoo.es.au

\section{INTRODUCTION}

Concussion in sport is a rapidly growing issue world-wide, not only in contact sports where concussion is now a major issue, but also in non-contact sports such as tennis. In contact sports, investigation of concussion has focussed on the long-term consequences of repeated head injuries during a professional athlete's career (Pearce et al., 2014). Concern has also been raised about players continuing or returning to play following impact to the head where the likelihood of further injury is significantly increased (Nordström et al., 2014).

Concussion and tennis are not normally words that would be used within the same sentence. Concussion rates in tennis are statistically negligible (Pluim et al., 2006). Recently however, several highly ranked players have been public with their struggles recovering from this injury, that we thought it was prudent to discuss concussion in tennis, particularly with regards to understanding what a concussion is, how to recognise the signs of concussion on the tennis court, when is a player ready to return to training and playing, and finally understand the issue of post-concussion syndrome.

\begin{tabular}{|c|c|c|}
\hline Causes of concussion & Onset of symptoms & Noticeable symptoms \\
\hline $\begin{array}{l}\text { Direct impact to head } \\
\text { (i.e. from tennis ball) }\end{array}$ & Immediate & $\begin{array}{l}\text { Loss of consciousness only in } \\
\text { 5-20\% of cases (Finch et al., } \\
\text { 2013; Meehan et al., 2010). }\end{array}$ \\
\hline $\begin{array}{l}\text { lead hitting hard surface } \\
\text { (i.e. tripping during warm up } \\
\text { or play) }\end{array}$ & $\begin{array}{l}\text { Delayed - by minutes or } \\
\text { sometimes by hours or days. }\end{array}$ & $\begin{array}{l}\text { Headache; nausea, blurred } \\
\text { vision, fatigue. }\end{array}$ \\
\hline \multirow[t]{2}{*}{$\begin{array}{l}\text { Indirect force to upper } \\
\text { body causing whiplash } \\
\text { action }\end{array}$} & & $\begin{array}{l}\text { Cognitive signs: loss in } \\
\text { memory; confusion; ability to } \\
\text { think; inability to focus. } \\
\text { Motor signs: slowness in } \\
\text { reaction; slurred speech; } \\
\text { impaired balance. }\end{array}$ \\
\hline & & $\begin{array}{l}\text { Descriptions: “...not quite } \\
\text { right", “...having my bell } \\
\text { rung", or “I couldn't see } \\
\text { anything for a couple of } \\
\text { seconds" (Ropper, 2008) }\end{array}$ \\
\hline
\end{tabular}

Table 1. Causes and noticeable signs of concussion (McCrory et al, 2013).

Recognising the signs of concussion

Sports-related concussion constitutes approximately $20 \%$ of mild traumatic brain injury cases, which itself makes up nearly $80-90 \%$ of all traumatic brain injuries (Langlois et al., 2006). The consensus statement following the 4th International Conference on Concussion in Sport defined concussion as a brain injury involving pathophysiological processes induced by biomechanical forces (McCrory, Meeuwisse, Aubry, Cantu, Dvoák, et al., 2013). Table 1 illustrates key causes and warning signs of concussion.

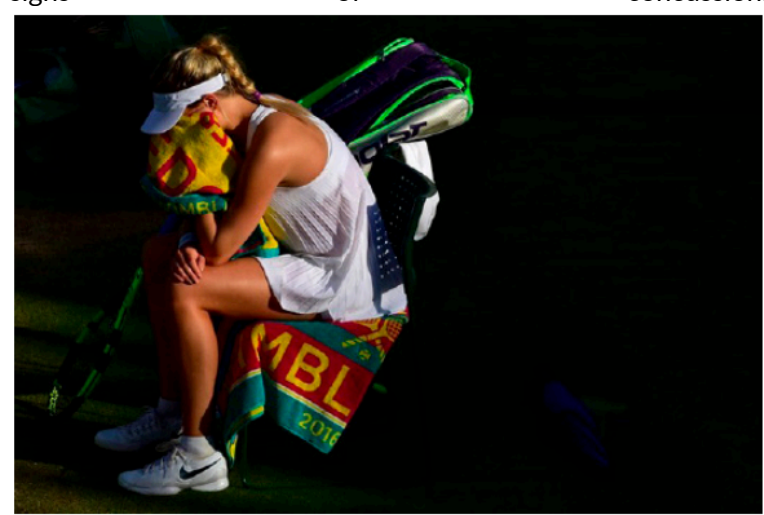

CONCUSSION IN TENNIS

Although rare, concussions in tennis players have occurred. Reports of players sustaining concussions indicate these are the result of falls, which is the most common reason for concussion injuries (Ropper, 2008). For example, Victoria Azarenka suffered concussion at the 2010 US Open when warming up and catching her foot at the bottom of her sweatpants. Azarenka went onto play her match but collapsed on court 30 minutes into the match. In the same year, British player Sarah Borwell was playing a doubles match when one of her opponents hit a smash impacting directly into Borwell's head (Myles, 2015). Feeling fine, Borwell continued to play, winning the match. However following the game symptoms appeared:

As soon as the adrenaline wore off I was a mess. I was feeling sick. I was dizzy, and my face swelled up on the left hand side... They monitored me for the evening, kept checking every hour and the next day, I had an MRI in San Francisco and they saw a bruise on my brain (Myles, 2015).

Despite the MRI findings, Borwell was told that she would be fine within seven days. Still feeling the effects of concussion (fatigued, photophobic and unsteady) Borwell continued to the next tournament and given a clearance that she could play. However, Borwell could not actually undertake any physical activity, finding difficulty in simple motor tasks such as walking straight and keeping her balance (Myles, 2015). It took nearly one year for Borwell's symptoms to dissipate. More recently Eugene Bouchard and Casey Dellacqua showed ongoing symptoms following their concussions after falls. Bouchard, falling in a change room accident, took over three months to 
recover from concussion (Henley, 2015). In October 2015 Dellacqua, falling on the court during a match in Bejing, missed the 2016 Australian summer season (Henley, 2015).

Importance of concussion awareness in tennis

In the USA, it is estimated that there are, per year, 1.6-3.8 million hospitalisations for sports- and recreation-related head injuries (Langlois et al., 2006). However, it is well known that sports concussion is often unrecognized, downplayed or dismissed and therefore goes unreported to doctors or a hospital, with the true incidence of concussion being estimated at a factor of 6 to 10 times more than what is officially recorded (Langlois et al., 2006). Although concussions in tennis are unlikely, it is possible that some players could be hit in the head with a ball or fall during play. Therefore it is important for coaches to be aware of how concussion can occur, ways to assess a concussion, how to manage a concussion, and to also to be aware of the signs of post-concussion syndrome or PCS (as highlighted in the examples of PCS with Borwell, Dellacqua, and Bouchard).

In contact sports, concussions can occur following a direct hit to the head, but this is not always the case with many concussions occurring from a violent bump or check to the upper body that can cause a whiplash action of the head (front to back, or side to side). However for tennis, concussions are likely to occur following a direct hit to the head (from either a tennis ball or head hitting the ground after falling). If a player is suspected of a concussion, they should be assessed using the Sports Concussion Assessment Tool-Version 3 (SCAT-3) by the tournament doctor (McCrory, Meeuwisse, Aubry, Cantu, Dvoøák, et al., 2013). The SCAT-3 comprises of eight sections covering symptom evaluation, cognitive and working memory evaluation, neck, balance and upper limb examination (for further information regarding the SCAT- 3 the reader is referred to McCrory et al (2013).

Current guidelines regarding the management of concussion, at present, suggest physical and cognitive rest should be prescribed until the acute symptoms resolve (McCrory et al., 2013). However data is limited on the efficacy of complete rest after concussion, with some researchers questioning if rest is the best possible treatment (DiFazio et al., 2015). However there is consensus with regards to the suitability for individuals in returning to training and play, via a graded program of physical exertion, each stage completed without symptom present, required prior to medical clearance (McCrory et al., 2013).

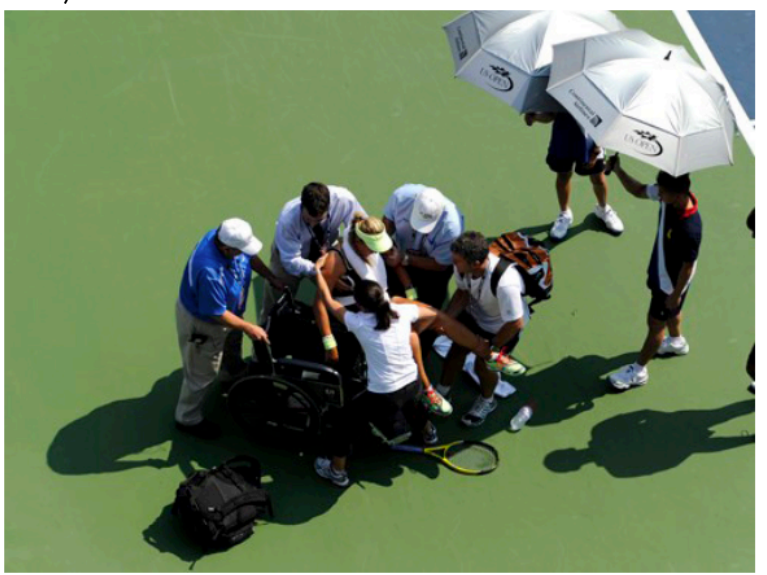

For a small number of individuals, concussion symptoms may not resolve. The cases of Borwell, Dellacqua, and Bouchard demonstrate that post-concussion syndrome (PCS) is a serious issue that can affect a player's career. In particular, the cases of
Borwell and Bouchard highlight the importance of return-toplay guidelines prior to returning to the court, with both players passing concussion assessments, yet were unable to play competitively. Table 2 lists the common symptoms of PCS that coaches can be aware of, the timeline that PCS can last for, and potential treatment options that can be prescribed by a medical practitioner or clinical psychologist.

\begin{tabular}{|c|c|c|}
\hline Symptoms reported & $\begin{array}{l}\text { Duration of symptoms } \\
\text { (20\% of those following } \\
\text { concussion) }\end{array}$ & Treatment options \\
\hline $\begin{array}{ll}\text { - } & \text { Headaches } \\
\text { - } & \text { Dizziness } \\
& \text { Fatigue (inability to } \\
\text { - } & \text { exercise) } \\
\text { - } & \text { Unitability } \\
& \text { concentrate } \\
\text { - } & \text { Visual disturbances } \\
\text { - } & \text { Memory impairment } \\
\text { - } & \text { Sensitivity to noise } \\
& \text { Depression and } \\
\text { anxiety }\end{array}$ & $\begin{array}{l}\text { - Weeks to months } \\
\text { Sometimes up to } \\
\text { year }\end{array}$ & $\begin{array}{ll}- & \text { Medication } \\
- & \text { Psychological } \\
& \text { support } \\
-\quad & \text { Cognitive- } \\
& \text { restructuring }\end{array}$ \\
\hline
\end{tabular}

Table 2. Characteristics of post-concussion syndrome

\begin{tabular}{|c|c|c|}
\hline Education & Training & Competition \\
\hline \multirow[t]{4}{*}{ First aid accreditation updated } & \multirow{4}{*}{$\begin{array}{l}\text { Clear courts of hazards (eg } \\
\text { hose removed from back of } \\
\text { court; balls cleared away and } \\
\text { not left on court) }\end{array}$} & $\begin{array}{l}\text { Responsibilities could include } \\
\text { ensuring and overseeing: }\end{array}$ \\
\hline & & $\begin{array}{l}\text { - Match conditions are safe } \\
\text { for players }\end{array}$ \\
\hline & & $\begin{array}{l}\text {-Venue and its facilities are } \\
\text { safe for all on site }\end{array}$ \\
\hline & & $\begin{array}{l}\text { This necessitates that } \\
\text { Occupational and Health } \\
\text { Safety policies for the match } \\
\text { venue are up-to-date and } \\
\text { implemented. Tournament } \\
\text { personnel may need to be } \\
\text { trained and briefed. }\end{array}$ \\
\hline \multirow[t]{3}{*}{$\begin{array}{l}\text { Concussion awareness } \\
\text { education (part of } \\
\text { professional development) }\end{array}$} & $\begin{array}{l}\text { Ensuring change rooms and } \\
\text { general facilities/areas are } \\
\text { free of hazards (e.g., slippery } \\
\text { and/or uneven surfaces) }\end{array}$ & $\begin{array}{l}\text { Coaches should have open } \\
\text { discussions with their players } \\
\text { about the risk of concussion } \\
\text { and how to best respond } \\
\text { to any such incident, erring } \\
\text { on the side of caution and } \\
\text { reporting it inmediately. } \\
\text { Physical well-being should } \\
\text { never be compromised ahead } \\
\text { of 'winning'. }\end{array}$ \\
\hline & $\begin{array}{l}\text { Phone access for medical } \\
\text { emergencies }\end{array}$ & \\
\hline & $\begin{array}{l}\text { Knowing and implementing } \\
\text { return-to-training protocols } \\
\text { through graduated increase in } \\
\text { physical activity }\end{array}$ & \\
\hline
\end{tabular}

Table 3. Implications for coaches in mitigating concussion injuries.

Tennis coach's role in concussion awareness

Coaches can play a significant role in mitigating risk of concussions in their players (Table 3 ). Firstly, coaches must be aware of their own knowledge limitations in this complex neurological condition; conversely, coaches must also be aware that their duty of care is enormous, given the potential of time lost for players to train and compete following a concussion injury.

It should also be noted that males and females can differ greatly in their symptomatic presentation, but as noted by Brown et al. (2015) differences can be explained by normal hormonal changes associated with the menstrual cycle. Conversely, it has been suggested that concussion symptoms can be downplayed by males (Sanderson et al., 2016). However, coaches should be aware of other coaches' attitudes towards concussion as many continue to underplay the potential seriousness of this injury (Caron et al., 2015).

\section{CONCLUSION}

Although concussion in tennis is rare, injuries have been documented in players with disturbing results. When medical professionals are not available, coaches should be concussion 
aware, given the current culture of players to 'underplay' the potential seriousness of their injury. Sideline concussion assessments are available and can assist in the evaluation of a player's injury and determination to return to play. However, further case studies detailing concussions during tournament play will assist with awareness of the issue.

\section{REFERENCES}

Brown, D. A., Elsass, J. A., Miller, A. J., Reed, L. E., \& Reneker, J. C. (2015). Differences in symptom reporting between males and females at baseline and after a sports-related concussion: a systematic review and meta-analysis. Sports medicine, 45(7), 10271040.https://doi.org/10.1007/s40279-015-0335-6

Caron, J. G., Bloom, G. A., \& Bennie, A. (2015). Canadian High School Coaches' Experiences, Insights, and Perceived Roles With Sport- Related Concussions.https://doi.org/10.1123/iscj.20150022

DiFazio, M., Silverberg, N. D., Kirkwood, M. W., Bernier, R., \& Iverson, G. L. (2015). Prolonged Activity Restriction After Concussion Are We Worsening Outcomes? Clinical pediatrics, 0009922815589914.https://doi.org/10.1177/000 9922815589914

Finch, C. F., Clapperton, A. J., \& McCrory, P. (2013). Increasing incidence of hospitalisation for sport-related concussion in Victoria, Australia. Medical Journal of Australia, 198(8), 427430.https://doi.org/10.5694/mja12.11217

Henley, B. (2015). Eugenie Bouchard, Casey Dellacqua And Concussions In Women's Tennis. Retrieved from http://espn. go.com/espnw/newscommentary/article/14290050/eugenie- bouchardcasey-dellacqua-concussions-women-tennis

Langlois, J. A., Rutland-Brown, W., \& Wald, M. M. (2006). The epidemiology and impact of traumatic brain injury: a brief overview. J Head Trauma Rehabil, 21(5), 375378.https://doi.org/10.1097/00001199200609000-00001

McCrory, P., Meeuwisse, W., Aubry, M., Cantu, B., Dvoøák, J., Echemendia, R., Engebretsen, L., Johnston, K., Kutcher, J., Raftery, M., \& Sills, A. (2013). SCAT3. British journal of sports medicine, 47(5), 259.

McCrory, P., Meeuwisse, W. H., Aubry, M., Cantu, B., Dvořák, J., Echemendia, R. J., Engebretsen, L., Johnston, K., Kutcher, J. S., Raftery, M., Sills, A., Benson, B. W., Davis, G. A., Ellenbogen, R. G., Guskiewicz, K., Herring, S. A., Iverson, G. L., Jordan, B. D., Kissick, J., McCrea, M., Mclntosh, A. S., Maddocks, D., Makdissi, M., Purcell, L., Putukian, M., Schneider, K., Tator, C. H., \& Turner, M. (2013). Consensus statement on concussion in sport: the 4th International Conference on Concussion in Sport held in Zurich, November 2012. Br J Sports Med, 47(5), 250-258. doi:10.1136/ bjsports-2013092313https://doi.org/10.1136/bjsports-2013092313

Meehan, W. P., d'Hemecourt, P., \& Comstock, R. D. (2010). High school concussions in the 2008-2009 academic year mechanism, symptoms, and management. The
American Journal of Sports Medicine, 38(12), 2405 2409.https://doi.org/10.1177/036354651037673 7

Myles, S. (2015). Concussions are rare in tennis, but when considering Eugenie Bouchard's case, remember Sarah Borwell. Retrieved from https://ca.sports.yahoo.com/blogs/eh-game/ concussions-are-rare-in-tennis--but-whenconsidering- eugenie-bouchard-s-case--considerthe-case-of-sarah- borwell-193510574.html

Nordström, A., Nordström, P., \& Ekstrand, J. (2014). Sportsrelated concussion increases the risk of subsequent injury by about $50 \%$ in elite male football players. $\mathrm{Br}$ J Sports Med, 48(19), 1447- 1450. doi:10.1136/bjsports-2013-093406 https://doi.org/10.1136/bjsports-2013-093406

Pearce, A. J., Hoy, K., Rogers, M. A., Corp, D. T., Maller, J. J., Drury, H. G., \& Fitzgerald, P. B. (2014). The long-term effects of sports concussion on retired Australian football players: A study using Transcranial Magnetic Stimulation. J Neurotrauma, 31, 1-7. https://doi.org/10.1089/neu.2013.3219

Pluim, B. M., Staal, J., Windler, G., \& Jayanthi, N. (2006). Tennis injuries: occurrence, aetiology, and prevention. British journal of sports medicine, 40(5), 415423.https://doi.org/10.1136/bjsm.2005.023184

Ropper, A. H. (2008). Concussion and other head injuries Harrison's principles of internal medicine. (pp. 25962600). New York: : McGraw-Hill Medical.

Sanderson, J., Weathers, M., Snedaker, K., \& Gramlich, K. (2016). "I Was Able to Still Do My Job on the Field and Keep Playing" An Investigation of Female and Male Athletes' Experiences With (Not) Reporting Concussions. Communication \& Sport.https://doi.org/10.1177/216747951562345 5

RECOMMENDED ITF TENNIS ACADEMY CONTENT (CLICK BELOW)

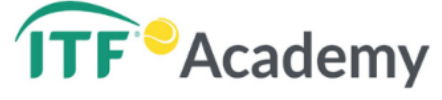

Copyright (c) Alan J Pearce and Janet A Young 2016

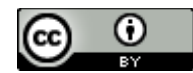

This text is under a Creative Commons BY 4.0 license

You are free to Share - copy and redistribute the material in any medium or format - and Adapt the content - remix, transform, and build upon the material for any purpose, even commercially under the following terms:

Attribution: You must give appropriate credit, provide a link to the license, and indicate if changes were made. You may do so in any reasonable manner, but not in any way that suggests the licensor endorses you or your use.

CC BY 4.0 license terms summary $\quad$ CCBY 4.0 license terms 